\begin{tabular}{|c|c|c|}
\hline 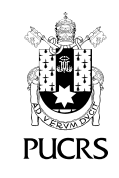 & $\begin{array}{l}\text { ESCOLA DE } \\
\text { HUMANIDADES }\end{array}$ & $\begin{array}{l}\text { Revista Digital do Programa de Pós-Graduação em Letras da PUCRS } \\
\text { Letrônica, Porto Alegre, v. 13, n. 1, p. 1-12, jan.-mar. } 2020 \\
\text { e-ISSN: } 1984-4301\end{array}$ \\
\hline def $\mathrm{http}: / / \mathrm{dx}$ & $\mathrm{rg} / 10.15448 / 1984-4301.2020 .1 .35148$ & \\
\hline
\end{tabular}

\title{
A literatura de autoria feminina no Brasil: um estudo sobre a trajetória de Francisca Júlia
}

\author{
The female authored literature in Brazil: a study on the trajectory of Francisca Júlia \\ La literatura de autoria femenina en Brasil: un estudio sobre la trayectoria de Francisca Júlia
}

\section{Jaqueline Ferreira \\ Borges $^{1}$ \\ orcid.org/0000-0002-7763-2917 \\ borrgesjaqueline@gmail.com.}

Recebido em: 30 jul. 2019.

Aprovado em: 4 out. 2019.

Publicado em: 7 abr. 2020

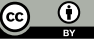

Artigo está licenciado sob forma de uma licença Creative Commons Atribuição 4.0 Internacional.
Resumo: Este artigo objetiva considerar a trajetória poética de Francisca Júlia da Silva Munster (1871-1920), escritora paulista que publicou quatro livros, sendo Mármores (1895), Livro da Infância (1899), Esphinges (1903) e, por último, em parceria com o irmão, publicou Alma Infantil (1920). A poeta foi uma das precursoras da inserção feminina na literatura a partir de uma perspectiva também feminina, pensando o corpo da mulher na literatura sob uma ótica também da mulher. A escritora enfrentou um sistema social pautado nos valores patriarcais e no silenciamento feminino, mas alcançou singular reconhecimento no cenário literário daquele periodo, no entanto, definhou-se ao longo do tempo até que se tornasse esquecida nas prateleiras das bibliotecas e carente de visibilidade e reconhecimento nos estudos científicos da atualidade. Para o embasamento teórico, alguns críticos foram considerados para subsidiar as discussões, principalmente, os estudos críticos de Ramos (1961) e Camargos (2007), pautados na trajetória poética de Francisca Júlia e no alcance de seu nome, seja em meados do século XX, seja nos anos seguintes de sua morte. Para além desses, outros teóricos, foram utilizados para compreendermos as temáticas e o modo como se organiza a sua produção poética.

Palavras-chave: Francisca Júlia. Historiografia literária. Autoria feminina. Parnasianismo. Simbolismo.

Abstract: This article aims to consider the poetic trajectory of Francisca Júlia da Silva Munster (1871-1920), a writer from São Paulo who published four books: Mármores (1895), Livro da Infância (1899), Esphinges (1903) and, finally, in partnership. with his brother, published Alma Infantil (1920). The poet was one of the precursors of the feminine insertion in the literature from a feminine perspective, thinking the woman's body in the literature from a woman's perspective. The writer faced a social system based on patriarchal values and female silencing, but reached singular recognition in the literary setting of that period, yet it faded over time until the writer became forgotten on library shelves and lacking visibility and recognition in today's scientific studies.For the theoretical basis, some critics were considered to support the discussions, especially the critical studies by Ramos (1961) and Camargos (2007), based on the poetic trajectory of Francisca Júlia and in the reach of her name, either in the mid-twentieth century,in the years following his death.Besides these, other theorists were used to understand the themes and the way their poetic production is organized.

Keywords: Francisca Júlia. Literary historiography. Female authorship. Parnasianism. Symbolism.

Resumen: Este artículo tiene como objetivo considerar la trayectoria poética de Francisca Júlia da Silva Munster (1871-1920), una escritora de São Paulo que publicó cuatro libros: Mármores (1895), Livro da Infância (1899), Esphinges (1903) y finalmente, en sociedad con su hermano, publicó Alma Infantil (1920). El poeta fue una de los precursores de la inserción femenina en la literatura desde una perspectiva femenina, pensando el cuerpo de la mujer en la literatura desde la perspectiva de una mujer. El escritor enfrentó un sistema social basado en valores patriarcales y silenciamiento femenino, pero logró un reconocimiento singular en el entorno literario de ese período, sin embargo, se desvaneció con el tiempo hasta que el escritor se olvidó en los estantes de la biblioteca y careció de visibilidad. y reconocimiento en los estudios científicos de hoy. Para la base 
teórica, se consideró que algunos críticos apoyaban las discusiones, especialmente los estudios críticos de Ramos (1961) y Camargos (2007), basados en la trayectoria poética de Francisca Júlia y en el alcance de su nombre, ya sea a mediados del siglo XX. en los años posteriores a su muerte. Además de estos, otros teóricos fueron utilizados para comprender los temas y la forma en que se organiza su producción poética. Palabras clave: Francisca Júlia. Historiografia literária. Autoria feminina. Parnasianismo. Simbolismo.

\section{Introdução}

A poeta Francisca Júlia nasceu em agosto de 1871, na antiga cidade de Xiririca, hoje conhecida como Eldorado, localizada no Estado de São Paulo. Filha do advogado Miguel Luso da Silva e da professora Cecilia Isabel da Silva, a educação foi um dos privilégios em que Francisca Júlia se apoiou para a sua inserção primeira no universo literário. Francisca Júlia começou a escrever ainda jovem, aos 14 anos, mais tarde já publicava em jornais e revistas e, em 1895, lançou o seu primeiro livro de poemas, Mármores. O incentivo familiar e as condições financeiras foram essenciais no processo de formação intelectual, de construção poética e do alcance à crítica literária.

Marcia Camargos (2007) salienta que Francisca Júlia herdou da mãe os dotes culinários; e do pai, o gosto pelos livros. Nesse sentido,

Há quem diga que este tenha sido o diferencial responsável por fazer de Francisca Júlia mais do que uma moça como todas as outras, cujo objetivo resumia-se a tornar-se prendada para conseguir um bom casamento e construir familia, gerando grande prole. Em vez disso, a garota de Xiririca nunca teve filhos e brilhou com luz própria no palco da literatura brasileira (CAMARGOS, 2007, p. 22).

Aos 37 anos, em 1909, Francisca Júlia se casou com Filadelfo Edmundo Munster e se afastou consideravelmente do espaço literário, dedicandose às atividades domésticas, assumindo a responsabilidade, a organização da família e o cuidado do esposo. Não obstante, a sua maior renúncia aconteceu aos 31 de agosto de 1920, após a morte de seu marido. Péricles Eugênio da Silva Ramos (1961) apurou que, "ouvindo testemunhas até oculares, foi que no dia da morte de Edmundo, Francisca Júlia se retirou para repousar. E não mais acordou, apesar dos esforços médicos para reanimá-la, vindo a falecer na manhã do dia do enterro do marido" (RAMOS, 1961, p. 21).

Os comentários sobre a morte de Francisca Júlia são diversos: no atestado de óbito, hemorragia cerebral; a notícia no Correio Paulistano defendia traumatismo craniano e indicando um possivel tiro na cabeça; já em O Estado de S. Paulo a notícia que se espalhava era que ela se deitou sobre o caixão para se despedir do marido e morrera ali mesmo, como se sussurrasse segredos nos ouvidos de Edmundo, e que quando o irmão foi retirá-la, já estava sem vida.

Após o falecimento, o nome da poeta perdeu muito de sua potência, a crítica esqueceu o nome de Francisca Júlia e as pesquisas seguiram por caminhos semelhantes. Os nomes masculinos de escritores e críticos ofuscaram outros tantos femininos, movimento que aconteceu por muito tempo na história da literatura brasileira. Como resultado, os escritos permaneceram, por muito tempo, esquecidos "nas estantes empoeiradas das bibliotecas e sem notícias de reedição" (PEREIRA, 2008, p. 94). Assim, Francisca Júlia, outrora reconhecida como fiel representante do parnasianismo e "dona de uma bela poesia, parece fadada ao esquecimento" (AYALA; DUARTE, 1997, p. 99).

Nesse sentido, este artigo traz possiveis respostas para o movimento de apagamento que se perpetua há muito, de uma escritora reconhecida em seu tempo, mas que atualmente é esquecida pela crítica e excluída dos manuais e dos livros de literatura. A dinâmica se perpetuou, sobretudo, por uma questão de gênero, e essa possibilidade que se apoia no conselho dado por José Severiano de Rezende, quando sugeriu a Francisca Júlia, que ela deveria se dedicar "aos trabalhos de agulha" (SILVA, 1894 apud RAMOS, 1961, p. 6).

A recomendação para que a escritora restringisse a sua dedicação à costura compreende a atividade doméstica de uma maneira bem mais ampla. Assim sendo, as questões de gênero desempenharam - e ainda desempenham - função decisiva na trajetória feminina, já que no cenário poético brasileiro mulheres como Júlia Lopes de Almeida, 
Gilka Machado, Nísia Floresta, Delminda Silveira e uma lista incansável de mulheres, contribuíram substancialmente para a literatura brasileira. Esses nomes colaboraram também para "essa geração pioneira das letras", mulheres que enfrentaram, no Brasil, "além dos preconceitos políticos, a discriminação sexual" (TELLES, 2010, p. 411).

Essas mulheres, conforme apresenta Zahidé Muzart (1999), não quiseram provocar apenas uma ruptura e introduzir a alteridade e a diferença, mas repensar a historiografia literária produzida por homens e a partir de uma perspectiva também masculina. Nesse sentido, e além de Francisca Júlia, outras escritoras brasileiras habitaram o espaço literário do século XIX.

Essas escritoras foram precursoras, especialmente, no que tange o empoderamento intelectual feminino, no entanto, foram suprimidas como se não as coubessem ao lado dos nomes masculinos. Outras mulheres estrearam a escrita literária e reelaboraram os seus destinos que há tanto haviam sido definidos, mas "muitas de nossas escritoras oitocentistas morreram e os escritos delas permaneceram nas gavetas de guardados para sempre" (SILVA, 2012, p. 45). Compreendendo que a crítica literária ofuscou tantos nomes, este texto é resultado de inquietações sobre a revisão do cânone e sobre o fortalecimento de nomes que contribuiram para a literatura brasileira de autoria feminina e requerem divulgação.

A escrita de Francisca Júlia apresenta uma nova proposta sobre o corpo feminino, esse descrito a partir de uma perspectiva da soberania. No entanto, apesar de o sujeito lírico reelaborar as possibilidades de ser das mulheres, não foram banalizadas as imposições atribuidas às damas da classe média alta que, observadas pelo seu grupo social, precisavam se comportar de acordo com as normas estabelecidas naquela época, como salienta Priore (2010):

A mulher de elite passou a marcar presença em cafés, bailes, teatros e certos acontecimentos da vida social. Se agora era mais livre - 'a convivência social dá maior liberalidade às emoções', não só o marido ou o pai vigiavam seus passos, sua conduta era também subme- tida aos olhares atentos da sociedade. Essas mulheres tiveram de aprender a comportar-se em público, a conviver de maneira educada (PRIORE, 2010, p. 191).

As mulheres oitocentistas começaram a frequentar os espaços públicos, mas seguindo o padrão de moça ideal. Se vistas na sociedade. pertenciam à elite e estavam sujeitas a respeitar comportamentos e atitudes especificos. Com o acesso à educação, elas puderam desconstruir as ideias apresentadas pelos escritores, bem como mostrar uma escrita de acordo com as suas próprias opiniões. Produziram textos em que o enredo não perpassava os espaços domésticos ou, tampouco, nos quais tratava de personagens romantizadas, como no poema "Venus" (SILVA, 1895, p. 15-16).

O soneto "Venus" trata da estátua de uma deusa hercúlea, grandiosa, heroica e que é colocada de pé, ou seja, o corpo está à mostra. O trono da rainha, esclarecida como escultura no segundo verso, é feito de mármore de Carrara, fazendo jus ao título Mármores desde já que estamos diante de uma figura mitológica e feita de pedra, rígida, dura, definida e rigorosa, colocada "em severa postura" (SILVA, 1895, p. 15).

Os poemas, principalmente de Mármores (1895) e Esphinges (1903), evidenciam o corpo nu de figuras femininas, descrevem as curvas e apresentam sujeitos líricos a partir de uma perspectiva do corpo autônomo, propriedade da mulher e não mais objeto social e do desejo masculino. Há uma reelaboração das descrições dos sujeitos líricos, os quais são colocados a partir de duas perspectivas: uma política; e a outra reivindicatória. Essas perspectivas são construidas a partir de uma vertente feminina que, apesar de ocupar um lugar social privilegiado, não possuía autorização para intervir no sistema social de meados do século XX.

Marcia Camargos (2007) trata da semelhança entre a descrição da escultura "Venus", no poema de mesmo nome, e a imagem² esculpida por Victor Brecheret, a qual veio de Paris e está hoje na Pinacoteca do Estado de São Paulo, admitindo que "a escultura representa tão perfeitamente 
o universo parnasiano na frieza impessoal das suas formas que parecem saidas de uma leitura post mortem deste poema" (CAMARGOS, 2007, p. 104). Em "Venus", o eu lírico contempla o objeto a sua frente, descrevendo a estátua como se a observasse minuciosamente e contemplasse o mármore que a constituía. Como pode se observar no poema abaixo, o qual foi dedicado à Victor Silva:

\section{Venus $^{3}$}

\section{A Victor Silva}

Branca e herculea, de pé, num bloco de Carrara,

Que lhe serve de throno, a formosa esculptura, Venus, tumido o collo, em severa postura,

Com seus olhos de pedra o mundo inteiro encara.

Um sopro, um quê de vida o gênio the insuflára; E impassivel, de pé, mostra em toda a brancura, Desde as linhas da face ao talhe da cintura, A magestade real de uma belleza rara.

Vendo-a nessa postura e nesse nobre entono De Minerva marcial que pelo gladio arranca, Julgo vel-a descer lentamente do throno,

E, na mesma attitude a que a insolencia a obriga, Postar-se á minha frente, impassivel e branca, Na regia perfeição da formosura antiga (SILVA, 1895, p. 15-16).

A construção do soneto é calcada na admiração e na magnitude da figura [feminina] observada, e a descreve de modo a aproximar as características da escultura a de um corpo feminino. O mármore, material que constitui a escultura de "Venus", está presente não somente nesse poema, mas também em vários outros versos da poeta. A rigidez da pedra muito se aproxima às caracteristicas do movimento literário, o qual renuncia o sentimentalismo do romântico e instaura a impassibilidade. O mármore lapidado, assim como os poemas, constrói estátuas, deusas e figuras femininas, apresentando traços delineados e uniformes ao mesmo tempo em que evidencia a rigidez do mármore.
Ainda a respeito do soneto "Venus", ele é potente, todo ele é poder. Duplamente metafórico, primeiro temos uma mulher viva, rigida como uma pedra, por outro lado temos uma escultura de rocha metamórfica, logo, sem vida. Em Francisca Júlia, não só a rigidez do mármore representa o parnasianismo, mas, também, a descrição detalhada e erótica dos corpos femininos. O desejo aí, ainda que cuidadosamente apresentado, perpassa especialmente. Mármores e Esphinges, os livros infantis, por sua vez, seguem um caminho temático bastante distinto e os sujeitos femininos são apresentados de maneira oposta, associadas à maternidade e aos cuidados domésticos e educacionais.

A dificil inserção da literatura de autoria feminina e o apagamento posterior da escritora e de seus escritos são justificáveis a partir da construção social de mulheres predestinadas a corresponder um modelo feminino ideal, submisso e obediente, fosse ao sistema político e social, fosse a figura masculina diretamente ligada a esses corpos. Segundo Schwants (2006), esses ideais femininos:

\begin{abstract}
baseiam-se no principio que as relações de família, notadamente casamento e maternidade. são a fonte da realização de uma psique feminina normal - dai decorrendo as diferentes formas de exclusão da mulher do mercado de trabalho e, mesmo quando a absorção ocorre, a atribuição do trabalho doméstico quase que exclusivamente à mulher (SCHWANTS, 2006, p. 10).
\end{abstract}

A ideia de que a capacidade cognitiva era inferior em relação ao homem nada mais é que o resultado de uma problemática de gênero que atribui às mulheres fragilidade e incapacidade intelectual, fruto da misoginia que reduz o feminino a uma posição inferior em relação ao homem.

O tema da autoria feminina é muito caro para a literatura feita por mulheres, principalmente, porque trata do direito à escrita, do direito à voz e a um posicionamento social e político. Essa abordagem é o resultado de questionamentos e da maneira pela qual as mulheres podem falar de si, de seus corpos, de sua sexualidade, de seus direitos e de liberdade. No que se refere à literatura de Francisca Júlia, temos "um feminino deslocado

3 O poema não possui acentuação, possivelmente uma característica da norma padrão daquele periodo. 
e transgressor, que reivindica agência e voz, em meio ao silenciamento" (BORGES, 2013, p. 28).

Márcia Camargos (2007) salienta que "das mulheres tidas como intelectualmente inferiores se esperavam clichês românticos, piegas e sentimentalistas" (CAMARGOS, 2007. p. 24). As mulheres que não corresponderam às expectativas sofreram a incompreensão dos que viam as formas e o conteúdo literário de modo restrito e uniforme. Foi nesse espaço que Francisca Júlia conquistou reconhecimento, embora de modo árduo e trabalhoso, pois os poetas daquele período demoraram a acreditar que suas produções literárias, cuidadosamente elaboradas, obedientes ao Parnasianismo, marcadas pela perfeição dos versos e pelo culto da forma, fossem de autoria feminina. Suspeitavam que se tratava do pseudônimo de algum poeta já conhecido e respeitado, mas jamais consideraram que as poesias poderiam ter sido escritas por uma mulher, dando pistas de marcas da misoginia e do desmerecimento ao qual o sexo feminino estava submetido naquela época: a habilidade literária e intelectual era exclusiva do homem.

José Severiano de Rezende, escritor simbolista brasileiro, foi um dos literatos que não reconheceu a poesia de Francisca Júlia naquele momento e, segundo ela mesma relata: "dedicou-me algumas linhas pela imprensa, em que me aconselhava a que não escrevesse mais versos, e terminava assim, se não me falha a memória: 'Minha senhora, há ocupações mais úteis: dedique-se aos trabalhos de agulha'". (SILVA, 1894 apud RAMOS, 1961, p. 6). João Ribeiro dedicou um poema como resposta a essas publicações ${ }^{4}$ em A semana e utilizou-se do pseudônimo de Maria Azevedo: "Eu respondo a esta imaginária poetisa" (FLEIUSS, 1941, p. 40-45 apud RAMOS, 1961, p. 7) e publica "Jazigo" em A semana, em 24 de março de 1894:

Narra Max Fleiuss que, ao serem publicados pelo periódico de Valentim Magalhães os primeiros versos de Francisca Júlia, João Ribeiro não acreditou que se tratasse de mistificação, atribuiu-os a Raimundo Correia. Araripe Júnior e Lúcio de Mendonça riram-se e também duvidaram (RAMOS, 1961, p. 7)

Considerando que se tratava da sátira de algum poeta, João Ribeiro optou por enfrentá-lo no gracejo, esclarecendo posteriormente que Francisca Júlia era de fato uma, cujo nome logo ganharia destaque por suas produções. As dúvidas a respeito da capacidade intelectual das mulheres sempre foram sustentadas pelos ideais patriarcais e misóginos que regiam a sociedade daquele periodo e que se fortaleciam a partir de comportamentos como os de João Ribeiro, Raimundo Correia, Araripe Júnior e Lúcio de Mendonça.

Em contrapartida às críticas, à medida que Francisca Júlia escrevia os seus poemas e outros textos poéticos apresentados posteriormente, a admiração e o respeito pelo seu trabalho poético se fortaleciam. Isso motivou para que em 1895 publicasse sua primeira obra, Mármores, a qual foi dedicada aos seus pais e prefaciada por João Ribeiro, jornalista, historiador e importante crítico literário daquele período. O prefácio pode ser visto não só como uma forma de admiração pela poética de Francisca Júlia, mas também como uma maneira de se redimir, tendo em vista que ele, inicialmente, havia duvidado da autoria dos versos.

No que se refere às temáticas dos poemas, Camargos (2007) reconhece ter sido Francisca Júlia a única parnasiana no Brasil conseguiu alcançar os ideais do movimento:

\begin{abstract}
Com efeito, mantendo um repertorio temático de gosto Greco-latino e cultivando sonetos derivados dos poetas-homens que supunha seus mestres, Francisca Júlia conseguia apaziguar as ânsias e emoções, domesticadas em favor da objetividade e dos rigorosos compromissos formais. Por isso parece ter sido a única porta-voz do movimento que, no Brasil, logrou atingir todos os objetivos do parnasianismo no ideal de beleza e impassibilidade em que outros poetas, inclusive Bilac, não obtiveram êxito semelhante. Foi plástica e sonora, professou a arte [...] e desejou a austeridade formal (CAMARGOS, 2007, p. 30).
\end{abstract}

A sua primeira obra propôs uma desconstrução social que perpassava a literatura de seu tempo

\footnotetext{
4 Ramos (1861) relata que até o momento a escritora já havia publicado, periódicos e revistas, os poemas "Musa Impassivel I", "D. Alda", "Sonho Africano", "A Caçada" e "Os Argonautas" (RAMOS, 1961, p. 7).
} 
e reforçava o machismo a partir da ideia de que a literária feminina era intelectualmente inferior a masculina. No entanto, Mármores foi uma obra elogiada, logo respeitada, e também responsável por lançar Francisca Júlia enquanto escritora, contribuindo para a quebra do paradigma de que a escrita feminina era menor.

A publicação de Mármores foi recebida com entusiasmo não somente em São Paulo, mas também no Rio de Janeiro e em vários lugares do País. Ramos (1961, p. 9) salienta que "Olavo Bilac louvou em FJ o culto da forma, a língua, remoçada 'por um banho maravilhoso de novidade e frescura'". Araripe Junior apontou que Francisca Júlia 'espreita o tempo das andorinhas para saltar voo', salientando ainda titulos como "D. Alda", "Sonho Africano" e "A caçada", de modo que esses poemas se afiguravam como joias literárias.

Francisca Júlia ultrapassou as demarcações femininas de seu tempo e habitou um universo intelectual onde a figura masculina era predominante. Vale destacar que a poeta conquistou respeito e admiração de diversos poetas e críticos literários no cenário patriarcal do século XIX, o qual oferecia principalmente o espaço doméstico às mulheres. $O$ primeiro livro da escritora marca a virada da recepção, pois traz o prefácio feito por João Ribeiro, importante crítico literário daquele período. Foi diante de diagnósticos positivos no que se referia à escrita da poeta, que o jornal $A$ Semana anunciou, em 16 de fevereiro de 1895, que publicaria o seu primeiro livro.

Já o segundo livro da escritora, Livro de Infância, de 1899, é composto por textos em prosa e em verso e, conforme esclarecido no prefácio feito pelo irmão da poeta, Júlio César da Silva (18731936), o livro é proposto "ás creanças que já tenham feito seu curso elementar de leitura e se achem habilitadas a iniciar estudos menos fáceis" (SILVA, 1899, p. 5). Ele concebia a literatura como algo elevado, superior e hermético. As considerações que faz são tão rigorosas quanto a escrita da irmã, defendendo que o livro se destinava às crianças com leituras mais desenvolvidas, elemento essencial para a compreensão dos versos.

Como a edição de Mármores não foi suficiente para atender a todos os interessados, em 1903, Francisca Júlia publicou Esphinges, que contém poemas já publicados em Mármorese e outros inéditos. Ramos (1961) salienta que foram excluidas 7 composições: "La Prude", "Estela" “No Boudoir", “No Baile", “Laura”, "Quadro Incompleto" e "Prece"; e acrescentados 14 poemas inéditos: "Dança de Centauras", "Anfitrite", "Profissão de fé", "Adamah", "Cega", "Crepúsculo", "Natureza", "Ângelus", "O Mergulhador", "De Crisós tomo Medjid", "Amor Descoberto", "Pranto de Luar", "Vida" e, por fim, "Alma e Destino". Além dos poemas que foram resgatados de Mármores, Esphinges também se compõe de mais seis textos da obra Livro da Infância, são eles: "Aguarella", "A Primavera", "Noite de Inverno", "Inverno", "O Ribeirinho" e a narrativa "De volta da guerra".

A segunda edição de Esphinges, publicada em 1921, apresenta uma versão revisada e reorganizada pelo irmão da poeta e divulgada pela editada Monteiro Lobato, resultada de toda a comoção diante da morte de Francisca Júlia, ocorrida um ano antes da reedição do livro. Pereira Neto (2013a) afirma que:

Quando da morte da poeta Francisca Júlia, em 1920, houve bastante comoção, várias cartas de lamentação em jornais [...]. A reedição de Esphinges, em 1921 se ligava a essa comoção pela morte da autora e primava pelo esmero da capa em preto e laranja com motivos egipcios, bem como pela folha de rosto ricamente ilustrada (PEREIRA NETO, 2013a, p. 8-9).

Ao lançar Esphinges em 1903, Francisca Júlia anunciou que trabalharia em um outro livro com possivel titulo Misticas, o qual seria uma espécie de obra reunida. Segundo Camargos (2007), Francisca Júlia havia anunciado também que elaboraria "um curso de literatura para uso dos ginasianos de São Paulo, assim como Místicas, obra poética definitiva. Por razões desconhecidas, tais projetos não chegaram a se concretizar" (CAMARGOS, 2007, p. 35). Diante da precoce morte da poeta, o livro prometido jamais foi publicado e quiçá elaborado.

Por fim, Francisca Júlia lançou o quarto e último livro infantil, intitulado Alma Infantil (1912), escrito em parceria com seu irmão, Júlio César da Silva. A obra oferece poesias de cunho religioso e 
educador, bem como "Recitativos, monólogos, diálogos, comédias escolares, brincos infantis, hymnos", conforme apresentados na capa da obra. Seguindo as mesmas temáticas que o Livro da Infância (1899), esse último atingiu também o público infantil e as turmas iniciais das escolas públicas do estado de São Paulo.

A recusa inicial se instaurou na trajetória da poeta e, apesar da laboriosa inserção, revisitar o percurso literário da escritora seria reconhecer os tantos universos e possibilidades que o leitor pode desfrutar diante dos versos da poeta parnasiana, aquela que foi equiparada a tríada, mas que jamais a compôs.

Há uma liberdade na escrita de Francisca Júlia, a qual transita não somente pelas diversas temáticas, mas também nas várias possibilidades de escrita literária. Em Mármores, temos especialmente os sonetos, preferência entre os parnasianos, assim como a exploração da arte pela arte, conceito que marcou as produções parnasianas, preocupando-se com a estrutura, a métrica e a musicalidade.

Há como imposição do movimento o cuidado formal na elaboração e no uso da linguagem nos poemas, consideravam-se a métrica, o ritmo e as rimas como artifícios essenciais. As rimas ricas, a elevação dos objetos e dos elementos da natureza também foram estratégias de construção de seus versos, conforme o soneto "Musa Impassivel", poema que marca a trajetória da poetisa e que recebe o título do poema como nome: "Versos que lembrem, com seus bárbaros ruidos,/ Ora o áspero rumor de um calháo que se quebra,/ Ora o surdo rumor de mármores partidos" (SILVA, 1895, p. 2).

A poeta respeitou o rigor do movimento, fosse nas temáticas, fosse na estrutura. Nomes como de Machado de Assis reiteraram sobre a escrita da poeta, a qual respeitou a estrutura poética aclamada pelo parnasianismo. Escreveu uma crônica 14 de julho de 1895 e enviou para A semana, apurando a mitologia e a impassibilidade dos versos:

Francisca Júlia da Silva, a patricia nossa, se é certo o que nos conta João Ribeiro, no excelente prefácio dos Mármores, já escrevia versos aos quatorze anos. Bem podia dizer, pelo estilo de Bernardim: 'Menina e moça me levaram da casa de meus pais para longes terras'... Essas terras são as da pura mitologia, as de Vênus talhada em mármore, as terras dos castelos medievais, para cantar diante deles e delas impassivamente. "Musa Impassivel", que é o título do último soneto do livro, melhor que tudo pinta esta moça insensivel e fria. Essa impassibilidade será a própria natureza da poetisa, ou uma impressão literária? Eis o que nos dirá aos vinte e cinco anos ou aos trinta. Não nos sairá jamais uma das choramingas de outro tempo; mas aquele soneto da p. 74, em que "a alma vive e a dor exulta, ambas unidas", mostra que há nela uma corda de simpatia e outra de filosofia (ASSIS, 1895 apud PEREIRA NETO, 2013, p. 14).

Francisca Júlia, decididamente parnasiana, por ela e pela crítica, vai muito além das imposições da escola, mostra-se fiel ao movimento, mas utiliza das mesmas características para transgredir, ou seja, ainda que ela respeite as imposições da escola, ela se opõe ao silenciamento feminino, congruente ao sistema patriarcal.

No que toca as vozes de seus poemas, os diferentes sujeitos líricos se revelam também de diferentes maneiras e com uma infinidade de comportamentos, variando entre as figuras fortes e impassiveis, como em "Venus" (SILVA, 1895, p. 1516), "Pérfida" (SILVA, 1895, p. 79-80) e "Amphitrite" (SILVA, 1903, p. 15-16), mas reproduzindo também alguns estereótipos femininos como a submissão, a fragilidade e a delicadeza, exemplificados nos poemas "Paula" (SILVA, 1912, p. 118-119), "Infância e Velhice" (SILVA, 1912, p. 53-54) e "Prece" (SILVA, 1912, p. 70-71). Esses últimos poemas apresentam caracteristicas bastante recorrentes às mulheres daquele periodo, respeitando os estereótipos, aspecto esse que justifica a amplitude e a diversidade das (des)construções do feminino oitocentista na poesia de Francisca Júlia.

Diante das diversas possibilidades de construção dos sujeitos líricos femininos impassiveis, temos uma proposta de desconstrução do modelo patriarcal e androcêntrico do século XIX, o qual resume as mulheres ao lar e aos cuidados da familia. A representação do feminino em Francisca Júlia transita tanto no universo da subversão quanto no cenário do tradicional e da obediência às imposições sociais, como é possivel notar nos dois livros infantis publicados pela escritora, primeiro Livro da Infância (1899) e, depois, em 
parceira com o irmão, Alma Infantil (1912).

Apesar de a escritora ter respeitado os moldes parnasianos, ela assumiu certa flexibilidade ao tratar de temas distintos, transitando pelo simbolismo, no terreno espiritual e místico, principalmente em Mármore (1895) e em Esphinges (1903). O primeiro sendo obediente às imposições parnasianas e o outro sendo simpático às características simbólicas, ambas propostas transgressoras no que tange o corpo feminino, como é possivel notar em "Pérfida" (SILVA, 1895, p. 79-80).

A partir do título desse poema, o qual dignifica "falta à fé jurada; desleal, traidor" (HOUAISS; VILLAR, 2009, p. 1472), temos a primeira desconstrução da imagem feminina, apresentada pelo poema, reelaborando a ideia do apego e do sentimental atribuido às mulheres. Em "Pérfida", o feminino nega o romantismo e assume independência sentimental e sexual, inclusive em relação às memórias do parceiro. No poema, o termo não é colocado de modo positivo, as definições de pérfida oferecem à figura feminina a posição de perversa e insensivel, contrário ao que se espera das mulheres oitocentistas.

Autores e críticos literários aclamados como Alfredo Bosi (2015) relataram sobre a qualidade nas produções da poeta, valorizando, na maioria das vezes a estrutura que os poemas apresentavam e a obediência às escolas literárias - Parnasianismo e Simbolismo. Simões Junior (2006, p. 16) ressalta que "convém lembrar que a poetisa estreara em 1895 com Mármores, um livro tipicamente parnasiano". Pereira Neto (2013a, p. 23) reforça que "à primeira vista, a obra poética de Francisca Júlia é tida como puramente parnasiana". Assim como a grande maioria dos trabalhos científicos em que protagoniza, a poetisa é definida enquanto devota desses dois movimentos literários, especialmente o parnasianismo. Tardelli (2015), em seu livro A torre
Invedada, trata, por outro lado, sobre a intrínseca relação entre a poeta e o Parnasianismo, mas a defende também simpática ao simbolismo.

No soneto "A noite" (SILVA, 1895, p. 33, 34), há um tom melancólico. Nele a dor exulta e a alma se abandona pelos enganos. Já no primeiro verso há uma imensidão nebulosa, a dor, o inalcançável e o inapreensivel são avaliados. A morbidez, a tristeza e a solidão são aspectos em evidência. O misticismo também se instaura quando a noite metaforiza o corpo mórbido, a alma ganha vida, está cheia de dor e se abandona aos enganos. A poeta simbolista sugestiona, é subjetiva, utiliza-se de musicalidade, além de explorar o místico, o mistério espiritual, explorando nessa medida o simbolismo, assim como Cruz e Souza.

Apesar de serem dois movimentos distintos, é razoável considerar os versos de Francisca Júlia como o resultado de ambas escolas. A poeta assumiu uma postura "antirromântica", conforme pedia o Parnasianismo, no entanto, tratou também de questões relacionadas ao misticismo, incluindo religiosidades e mitologias. Nessa esteira, Ramos (1961, p. 17) constrói um momento de discussão em Poesias, intitulado "Feitiçaria, Lobisomem, corpo astral", quando aborda sobre a primeira conferência proferida por Francisca Júlia, em 1908, no salão do edifício da Câmara Municipal de Itu, onde ministrou palestras. Lôbo (1991, p. 216), de igual modo, aponta que:

Dotada de sentidos privilegiados, de uma sensibilidade à flor da pele, Francisca Júlia reagia ao menor estímulo externo do mundo físico. Ela pôde, assim, perceber os pequenos detalhes da natureza, que procurou transpor para os seus textos, criando, por vezes, imagens verdadeiramente sinestésicas, onde não só o visual e auditivo, mas também o olfativo, o gustativo e o tátil se confundem (LÔBO, 1991, p. 216).

misticismo ${ }^{5}$ da escritora é evidenciado

\footnotetext{
5 Essa vertente espiritualista sobrevive, ainda hoje, e dá nome ao Núcleo Espírita Francisca Júlia, que disponibiliza um site com informações importantes sobre o Núcleo e sobre a escritora. A sede tem endereço em Porto Alegre, oferece cursos e palestras, além de organizarem congressos e seminários - o último aconteceu em 26 de novembro de 2016, em Brasilia.

Além disso, o CVV- Centro de Valorização da Vida, fundado na década de 1990, e atuante em grande parte do Brasil, tem o objetivo de ajudar e aconselhar pessoas que apresentem indícios de depressão, buscando, assim, evitar atitudes decisivas dessas pessoas contra a própria vida. Esse grupo tem raiz no espiritismo e surgiu a partir de colocações de Francisca Júlia desencarnada, conforme defende os fundadores do grupo, informado em uma conversa informal.

A partir do CVV, um hospital psiquiátrico foi fundado e tem sede hoje em São José dos Campos. A unidade de nome Hospital Francisca Júlia, conta com médicos especializados, mas a influência do espiritismo é inegável. Este grupo, assim como o de Porto Alegre, defende que o espírito de Francisca Júlia se posiciona contra o suicídio. Há uma relação entre a escritora e a abordagem kardecista, inclusive há um poema que, intitulado por "Adeus" e psicografado por Chico Xavier e Waldo Vieira, foi publicado em Antologia dos Immortais (1963).
} 
também em seus poemas. Pereira (2008, p. 93) também destaca essa caracteristica de Francisca Júlia, apontando que ela "assume sua face mística e moralizante, aceitando convites para palestras sobre feitiçaria, corpo astral, mediunidade e reencarnação". A escritora não se filiou a nenhuma religião, o que a tornava ainda mais mística, enigmática e ascética. A transitoriedade nas várias crenças e a abordagem de figuras representativas e simbólicas demonstra sua liberdade mística em transitar nos mais variados universos.

Tratar a liberdade feminina em um contexto social oitocentista, em que o corpo da mulher era ainda mais excluso e exclusivo ao homem, oferece artificios para compreender Francisca Júlia enquanto uma poeta à frente de seu tempo, seja por evidenciar as figuras femininas; seja por descrever esses corpos; e ainda, por autorizá-los à sensualidade e ao erotismo, e; por oferecer espaços para esses corpos nus, rígidos e impassiveis em versos parnasianos assinados por uma mulher.

Francisca Júlia abordou o feminino em seus textos, apresentando figuras impassiveis e eróticas, descritas e observadas pelo sujeito lírico, o qual evidenciava o corpo e o nu feminino, detalhando a sensualidade, o erotismo e a impassibilidade, a ponto de desmistificar e retirar o corpo feminino da guarda dos escritores, evidenciando, ainda, o respeito e o domínio às imposições literárias clamadas em seu tempo.

O soneto "Rainha das águas" (SILVA, 1895, p. 9-10), dedicado ao parnasiano Alberto de Oliveira, obediente às práticas parnasianas, evidencia uma questão imagética, apresentando a descrição, constrói uma imagem seja de um quadro ou mesmo de uma escultura do objeto poético, aguçando os sentidos do leitor como se fosse possivel sentir e enxergar a figura. A descrição minuciosa oferece tanto a facilidade em figurar o lido, como também em evidenciar o erótico, dando detalhes e salientando as características da rainha.

\section{Rainha das águas}

A Alberto Oliveira

Mar fora, a rir,- da bocca o fulgido thesouro

\begin{abstract}
Mostrando, e sacudindo afarta cabelleira, Corta a planura ao mar, que se desdobra inteira, Numa varina azul orladurada de ouro.

Rema, á popa, um tritão de escameo dorso louro: Vão á frente os delfins; e, marchando em fileira, Das ondas a seguir a luminosa esteira,

Vão cantando, a compasso, as piérides em coro.

Crespas, cantando em torno, as vagas, em surdina, Lambem de popa á proa o casco da varina Que prosegue, mar fora, a infinda rota, ufana...

E, no alto, o louro sol que assoma, entre desmaios, Saüda esse outro sol de coruacantes raios Que orna a cabeça real da bella soberana (SILVA, 1895, p. 9-10)
\end{abstract}

A capacidade de dominar apresentada pela rainha é reforçada na segunda e na terceira estrofes quando o tritão e os delfins cantam em coro, em uma rota vaidosa e infinita. A cantoria é responsável por demonstrar alegria e satisfação das figuras que recebiam a rainha. A melodia representa sensações de felicidade por estarem próximas da Rainha das Águas. Havia, então, motivos para festejar. Alegravam-se demonstrando uma espécie de reverência nesse ato, como se louvassem uma figura imponente e soberana.

A supremacia da rainha se situa, principalmente, na majestade e na força que assume, dominando e tendo controle do vasto mar. Em relação ao corpo feminino, vimos que ele é responsável por caracterizar as mulheres e defini-las socialmente. Perrot (2005) defende que o corpo é o centro, bem como a sua aparência e os seus comportamentos:

O corpo está no centro de toda relação de poder. Mas o corpo das mulheres é o centro, de maneira imediata e especifica. Sua aparência, sua beleza, suas formas, suas roupas, seus gestos, sua maneira de andar, de olhar, de falar e de rir [...] são o objeto de uma perpetua suspeita. Suspeita que visa o seu sexo, vulcão da terra (PERROT, 2005, p. 447).

O erótico habita exatamente na descrição desses corpos que definem as mulheres e é capaz de despertar desejos. No poema, as descrições são breves, concentrando-se em 
associar traços do rosto e do cabelo a tesouros à majestade da moça.

A sensualidade da rainha situa-se na descrição de seus membros superiores, assim como salientado por Camargo (2013), demonstra a descrição de forma que a protagonista é elogiada, enaltecida e respeitada. Ou seja, os membros descritos dizem respeito aos membros superiores, como o sorriso, a boca e até os cabelos. Na boca ela tem tesouros e, além da farta cabeleira, é "o sol de coruscantes raios/ que orna a cabeça da bela soberana" (SILVA, 1895, p. 10).

Tratar o nu feminino de modo a evidenciar $e$ erotizá-lo é transgressor porque a sexualidade sempre foi um assunto discreto. Michel Foucault (2017) salienta a respeito da liberdade em falar sobre sexualidade, considerando que esse ainda é um assunto por demais vetado: "Se o sexo é reprimido, isto é, fadado à proibição, à inexistência e ao mutismo, o simples fato de falar dele e de sua repressão possui como que um ar de transgressão deliberada" (FOUCAULT, 2017, p. 11), e completa afirmando que se há discussão sobre sexualidade, tratar-se-á, possivelmente, de um caráter político ou militante. Próximo do que teorizou Foucault, Borges (2013) comenta sobre o estranhamento que pode causar uma literatura erótica de autoria feminina:

Se falar de sexo é, por si mesmo, uma transgressão, a escrita erótica das mulheres se configura como mais transgressora: culturalmente, as mulheres não estão autorizadas, pela lógica patriarcal e falocêntrica, a falar sobre sexo; elas são o sexo e, portanto, não falam, elas são faladas (BORGES, 2013, p. 109, grifo da autora).

Francisca Júlia evidencia a sexualidade e o nu feminino por meio do texto poético. Para Borges (2013, p. 28), essa temática faz parte de uma tradição que circunscreve "o corpo feminino como objeto do desejo masculino", desse modo, o espaço erótico "constitui um terreno discursivo no qual o olhar feminino esteve frequentemente ausente", ou seja, as mulheres não foram colocadas em evidência, apenas os seus corpos. Por esse motivo, Francisca Júlia transgrediu enquanto mulher e enquanto poeta.

Octávio Paz (2012) salienta sobre o dizer social e o poético e sobre a proximidade entre poesia e erotismo. Vejamos:

\begin{abstract}
A periculosidade da poesia é inerente a seu exercício e é constante em todas as épocas e em todos os poetas. Há sempre uma rachadura entre o dizer social e o poético: a poesia é a outra voz [...]. Por isso é, ao mesmo tempo, natural e perturbadora sua correspondência com os aspectos do erotismo [...]. Poesia e erotismo nascem dos sentidos, mas não terminam neles. Ao se soltarem, inventam configurações imaginárias - poemas e cerimônias (PAZ, 2012, p. 14, grifo do autor).
\end{abstract}

Segundo Octávio Paz (2012), pensar o erotismo nas poesias pode soar perturbador, porque, apesar de nascerem dos sentidos, não é onde terminam. O próprio fazer poético é um gesto criador e, por isso, erótico. Desse modo, poesia e erotismo estão muito próximos, dando abertura à possibilidade do duplo, da metáfora e da volúpia. Temos "um feminino deslocado e transgressor, que reivindica agência e voz, em meio ao silenciamento" (BORGES, 2013, p. 28), o qual surpreende e é construido como sinônimo de liberdade corporal e sexual, capaz de dominar o próprio corpo, sejam elas deusas, figuras mitológicas e/ou misticas.

\section{Considerações finais}

Ao associarmos, pois, as figuras ficcionais de Francisca Júlia às mulheres oitocentistas, compreende-se um diálogo entre esses dois femininos. Essa relação é compreendida através da representação literária que faz com que relacionemos ficção com realidade. Para Auerbach (2015), "a realidade, dentro da qual os homens vivem, modifica-se, torna-se mais ampla, mais rica em possibilidades e ilimitada; assim, ela também se modifica, no mesmo sentido, quando se torna objeto da representação" (AUERBACH, 2015. p. 286). É diante da possibilidade do fazer literário se (trans)formar que se assemelham e transitam a convergência entre o real e o ficcional.

A poesia de Francisca Júlia assume uma perspectiva política e reivindicadora, principalmente no que tange a independência feminina em relação ao homem e a descrição dos corpos. Adorno (2003) aponta que o poema não 
é construido pela mera experiência, é necessária a forma estética para ganhar alcance artístico, desse modo, a universalidade do poema está calcada no "mergulho do individuado" que extrai da "composição lírica [...] a mais irrestrita individuação, o universal" (ADORNO, 2003, p. 66).

Considerando a poesia como ato reivindicatório e, portanto, criação política, utiliza-se da linguagem e desvia de seu projeto primeiro: a comunicação. Paz (1993) aponta que a poesia põe o significado da linguagem entre parênteses, ou seja, utiliza-se da linguagem cotidiana, mas diz além, apontando que "há sempre uma greta entre o dizer e o dizer poético: a poesia é outra voz", (PAZ, 1993, p. 10), da mesma forma Francisca Júlia se utiliza da poesia para propor uma reelaboração do lugar no sistema, seja político e/ou literário.

\section{Referências}

AUERBACH, Erich. Mimesis. 6. ed. São Paulo: Perspectiva, 2015.

AYALA, Maria Ignez Novais; DUARTE, Eduardo de Assis. (org.). Múltiplo Mário: ensaios. João Pessoa, PB; Natal, RN: UFPB-Ed. Universitária; UFRN-Ed. Universitária, 1997.

BORGES, Luciana. O erotismo como ruptura na ficção brasileira de autoria feminina. Florianópolis: Ed. Mulheres, 2013.

BOSI, Alfredo. O ser e o tempo na poesia. São Paulo: Cultrix, 2000

CAMARGOS, Márcia. Musa Impassivel: a poetisa Francisca Júlia no cinzel de Victor da Costa Albuquerque et al. (Trad.). 4. ed. Rio de Janeiro: São Paulo: Paz e Terra, 2007.

NÚCLEO Espírita Francisca Júlia. Disponivel em: https://www.franciscajulia-ramatis.com.br/. Acesso em: 22 jan. 2020

FOUCAULT, Michel. A história da sexualidade: a vontade de saber. Maria Thereza da Costa Albuquerque et al. (Trad.). 4. ed. Rio de Janeiro: São Paulo: Paz e Terra, 2017.

MUZART, Zahidé L. (org.). Escritoras brasileiras do século XIX: antologia. Florianópolis: Editora Mulheres; Santa Cruz do Sul. EDUNISC, 1999, v. 1.

MUZART, Zahidé L. (org.). Escritoras brasileiras do século XIX: antologia. Florianópolis: Editora Mulheres; Santa Cruz do Sul. EDUNISC, 2004. v. 2

LÔBO, Danilo. Francisca Júlia: entre o pincel e a pena. Universidade Federal de SantaCatarina: Publicação do Programa de Pós-Graduação em Literatura. Florianópolis: Travessia, 1991.

PAZ, Octávio. O arco e a lira. São Paulo: Cosac Naify, 2012.
PAZ, Octávio. A chama dupla: amor e erotismo. Lisboa: Assírio e Alvim, 1993

PEREIRA, Kênia Maria de Almeida. A universidade e a formação do aluno leitor. Uberlândia: EDIBRÁS, 2008.

PEREIRA NETO, João Vicente. Oscilações líricas de uma musa impassivel: itinerário poético de Francisca Júlia no sistema literário brasileiro. 2013. 139 f. Dissertação (Mestrado em Literatura) - Universidade de Brasilia, Brasilia, DF, 2013. Disponivel em: http://repositorio.unb.br/bitstream/10482/14840/3/2013_JoaoVicentePereiraNeto.pdf. Acesso em: 10 jun. 2019. https:// doi.org/10.18840/1980-8860/rvmd.v10n1p354-377

PRIORE, Mary del (org.). História das mulheres no Brasil. 9. ed. São Paulo: Contexto, 2010. https://doi. org/10.4000/clio.210

RAMOS, Péricles Eugênio da Silva (org.). Poesias de Francisca Júlia. São Paulo: Conselho Estadual de Cultura, 1961.

SCHMIDT, Rita Terezinha. Para além do dualismo natureza/cultura: ficções do corpo feminino. Organon: Revista do Instituto de Letras da UFRGS, Porto Alegre, v. 27, n. 5, p. 1-20, 2012. https://doi. org/10.22456/2238-8915.33480

SCHWANTS, Cintia. Dilemas da representação feminina. OPSIS: Revista do NIESC, [S. l.], Goiânia, v. 6, p. 7-19, 2006. Disponivel em: https://www. revistas.ufg.br/Opsis/article/viewFile/9308/6400?journal=Opsis. Acesso em: 13 jun. 2019. https://doi. org/10.5216/o.v6i1.9308

SILVA, Francisca Júlia da. Alma Infantil. São Paulo e Rio de Janeiro: Livraria Magalhães, 1912.

SILVA, Francisca Júlia da. Alma Infantil. 2. ed. São Paulo: B4 kids, 2003.

SILVA, Francisca Júlia da. Esphinges. São Paulo: Bartley Junior e Companhia, 1903.

SILVA, Francisca Júlia da. Esphinges. 2. ed. São Paulo: Monteiro Lobato e Cia. 1921.

SILVA, Francisca Júlia da. Livro de Infância. São Paulo: Typographia Diário Oficial, 1899.

SILVA, Francisca Júlia da. Mármores. São Paulo: Horácio Belford Sabino, 1985.

SIMÔES JUNIOR, Álvaro Santos. Da literatura ao jornalismo: periódicos brasileiros do século XIX. Patrimônio e Memória, Marilia, v.2, n. 2, p. [1-20], 2006.

TELLES, Norma. Escritoras, escritas, escrituras. In: DEL PRIORE, Mary (org.). História das mulheres no Brasil. 9. ed. São Paulo: Contexto, 2010. p. 401-443. https://doi.org/10.4000/clio.210

SILVA, Marcelo Medeiros da. Poesia e resistência no Brasil: o caso das poetisas oitocentistas. Revista Artemis, Paraiba, v. 14, p. 44- 53, ago./dez. 2012.

TARDELLI, Caio Cardoso. A torre Invedada. São Paulo: Maça de Vidro, 2015

XAVIER, Francisco Cândido; Vieira, Waldo. Antologia dos Imortais. Brasilia: Federação Espírita Brasileira, 1963. 


\section{Endereço para correspondência}

Jaqueline Ferreira Borges

Universidade Federal de São Carlos

Rod. Washington Luis, km 235, SP-310, CECH, PPGLit.

13565-905

São Carlos, SP, Brasil

\section{Jaqueline Ferreira Borges}

Mestra em Estudos Literários, pela Universidade Federal de Uberlândia (UFU, Uberlândia, MG, Brasil), doutoranda em Estudos de Literatura pela Universidade Federal de São Carlos (UFSCar) em São Carlos, SP, Brasil. 